\title{
PUERTOS Y TURISMO DE CRUCEROS EN ISLAS DEL ATLÁNTICO MEDIO SEPTENTRIONAL (CARIBE Y MACARONESIA) ${ }^{1}$
}

\author{
Alejandro González Morales \\ Universidad de Las Palmas de Gran Canaria \\ alejandro.gonzalez@ulpgc.es \\ ORCID iD: https://orcid.org/0000-0002-2659-9678 \\ Antonio A. Ramón Ojeda \\ Universidad de Las Palmas de Gran Canaria \\ toni.ramon@ulpgc.es \\ ORCID iD: https://orcid.org/0000-0002-4578-5185
}

Recibido: 29-05-2019 Aceptado: 27-04-2020

\begin{abstract}
Cómo citar este artículo/Citation: González Morales, Alejandro y Ramón Ojeda, Antonio A. (2020). Puertos y turismo de cruceros en islas del Atlántico medio septentrional (Caribe y Macaronesia). Estudios Geográficos, 81 (288), e039. https://doi.org/10.3989/ estgeogr.202054.044

RESUMEN: El presente trabajo realiza una aproximación al turismo de cruceros en el Atlántico Medio Septentrional. Se estudian las características de los puertos, rutas y destinos del Caribe y la Macaronesia, estableciendo un análisis comparado e individual de cada ámbito. Se analiza el número de cruceros, su frecuencia, estacionalidad y duración, las principales rutas, los recursos más visitados y también las características de los puertos, de los que se elabora una propuesta tipológica. Se han observado algunas similitudes entre ambos espacios, pero sobre todo existen diferencias, tanto cuantitativas, como cualitativas. Asistimos a una transformación del modelo de turismo de cruceros que es resultado del crecimiento de este segmento, lo que está dando lugar a nuevas formas de utilización del territorio y sus recursos. Los puertos se transforman con rapidez debido a las inversiones en infraestructuras, pero su localización es cada vez menos determinante en el diseño de las rutas.
\end{abstract}

PALABRAS CLAVE: turismo de cruceros; puertos de cruceros; Caribe; Macaronesia

\section{PORTS AND CRUISES IN ISLANDS OF NORTH MID-ATLANTIC (CARIBBEAN AND MACARONESIA)}

ABSTRACT: This work makes an approximation of cruise tourism in the North Mid-Atlantic. In the work we study the characteristics of the ports, routes and destinations of the Caribbean and Macaronesia, establishing a comparative and individual analysis of each area. This paper analyses the number of cruises, their frequency, seasonality, duration, the main routes, the most visited resources and the characteristics of the ports, from which a typological proposal is carried out. Some similarities have been observed between both spaces, but above all, there are differences, both quantitative and qualitative. We are witnessing a transformation of the cruise tourism model that is the result of the growth of this segment, which is giving rise to new ways of using the territory and its resources. Ports are being transformed quickly due to infrastructure investments, but their location is less and less decisive in the design of routes.

KEY WORDS: Cruise tourism; Cruise ports; Caribbean; Macaronesia.

Copyright: @ 2020 CSIC. Este es un artículo de acceso abierto distribuido bajo los términos de la licencia de uso y distribución Creative Commons Reconocimiento 4.0 Internacional (CC BY 4.0). 


\section{INTRODUCCIÓN}

El turismo de cruceros ha experimentado una notable evolución desde sus orígenes a finales del siglo XIX hasta la actualidad. En su concepción moderna, la que se aborda en el presente trabajo, surge en la segunda mitad del siglo XX, tras el declive de las rutas transoceánicas entre Estados Unidos y Europa (Brida, Bukstein y Tealde, 2015) y se desarrolla sobre todo a partir de los años 80 (Rodrigue y Notteboom, 2013). Desde comienzos del siglo XXI muestra un crecimiento acumulativo anual cercano al $8 \%$ (WTO, 2018) y del $62 \%$ en la última década (CLIA, 2017²).

En opinión de Cruz y Romero (2015) la mejora de los transportes, las estrategias de las principales compañías proveedoras de servicios turísticos y el abaratamiento de costes están facilitando el incremento del número de pasajeros a nivel mundial, dentro de un contexto general marcado por la globalización (Wood, 2000; Fernández, 2012).

El crucero oceánico es predominante por encima de rutas fluviales y lacustres. A nivel mundial destacan cuatro destinos: Caribe (38,7\% del mercado), Mediterráneo $(14,8 \%)$, Mar del Norte y Báltico $(9,4 \%)$ y Alaska (4,4\%) (Cruise Industry News, 2018: 9 y 17). El liderazgo en cuanto a volumen de negocios del Caribe es abrumador, pero el crecimiento del mercado está llevando a explorar nuevos espacios (Teye y Morris, 2011: 19), entre los que cabría destacar itinerarios en el Pacífico Norteamericano, en especial entre San Diego y Anchorage, las rutas antárticas con salidas desde Ushuaia y Punta Arenas, el Mar de China Meridional, los Mares del Sur y también los archipiélagos atlánticos de Canarias, Madeira y Azores, un destino aún minoritario pero en desarrollo.

Por tanto, el Atlántico medio septentrional acoge un destino plenamente consolidado y líder mundial en volumen de mercado como es el Caribe y también rutas emergentes y en rápido crecimiento que incluyen las islas macaronésicas de España y Portugal.

El objeto del presente estudio es realizar un análisis comparado sobre el turismo de cruceros en los espacios insulares del Caribe y la Macaronesia europea. El ámbito de estudio queda definido por los archipiélagos comprendidos entre las Penínsulas de Florida y Yucatán, y en el lado oriental las islas de Canarias, Madeira y Azores. El estudio se centra en los destinos y trayectos del mencionado ámbito geográfico, considerando principalmente puertos, rutas y recursos visitados.
Hay que advertir que la bibliografía especializada es abundante, especialmente para el Caribe. Cabe destacar los trabajos llevados a cabo sobre los efectos e impactos del turismo de crucero en la economía, sociedad, territorio y medio ambiente, como los realizados por Dwyer y Foryth (1998), Wood (2000), Braun et al. (2002), Kester (2002), Timothy (2006), Butler (2008) y Lee y Ramdenn (2013), todos ellos centrados en los efectos económicos y también en la evolución histórica de esta modalidad turística. Además, destacan en cuanto al análisis de los impactos sociales y ambientales las investigaciones de Wood (2000) y Brida y Zapata (2010), y sobre la gestión territorial los trabajos específicos de Braun et al., (2002), sobre Port Canaveral en Florida; el de Seidl, Guiliano y Pratt sobre Costa Rica (2006) o el de Palafox et al. (2015), sobre Cozumel.

La producción referida al Caribe es mucho más extensa, pero también existen trabajos interesantes sobre el Atlántico oriental, si bien en Europa la literatura científica sobre cruceros se centra especialmente en el Mediterráneo: Murias (2002), Brida y Zapata (2008), Andriotis y Argiomirgianakis (2010), Garay y Cánoves (2012), Legoupil (2013) y Luna (2015), entre otros. En estos trabajos la Macaronesia rara vez se aborda, o bien se hace de manera tangencial, lo que ya supone un hecho diferencial respecto al Caribe en cuanto a profusión de estudios. Aunque recientemente se han publicado algunos trabajos, como los de EDEI (2005, 2009 y 2016), Silvestre, Santos y Ramalho (2008), Andrade y Robertson (2010), Hernández et al. (2015), Esteve-Pérez, García-Sánchez y Gutiérrez (2015) y Fernández y Mayorga (2018), la producción científica referida a la Macaronesia sigue siendo exigua. Por ello, los datos manejados en el presente estudio provienen principalmente de fuentes estadísticas oficiales como las publicadas por las respectivas autoridades portuarias y la documentación que figura en sus archivos (para el caso macaronésico) y respectivas webs.

El trabajo se estructura en seis epígrafes. Este apartado inicial dedicado a la introducción y una breve sinopsis, probablemente incompleta, de referencias sobre el turismo de cruceros; fuentes y metodología, donde se exponen las principales fuentes de documentación y el proceso metodológico; dos apartados en los que se lleva a cabo una aproximación al turismo de crucero en los dos ámbitos geográficos considerados: Caribe y Macaronesia; una exposición de resultados referidos a los puertos y rutas de cruceros en los archipiélagos del Atlántico Medio Septentrional 
que incluye un análisis comparado entre ambos espacios y, finalmente, las conclusiones y referencias bibliográficas.

\section{FUENTES Y METODOLOGÍA}

Para abordar el presente trabajo se realiza en primer lugar una aproximación a la situación actual de ambos espacios, Caribe y Macaronesia, desde una perspectiva geográfica y diacrónica. Seguidamente, el estudio se centra en cuáles son los puertos principales y qué características reúnen los destinos y rutas, qué similitudes y diferencias pueden establecerse entre las dos orillas atlánticas y qué transformaciones se han producido y cómo se organizan los itinerarios en relación con los recursos territoriales y las escalas. Se estudian los tipos de puertos y destinos insulares, las características de las rutas y los recursos territoriales que constituyen los principales atractivos. El análisis se centra en los tipos de puertos y escalas, resaltando especialmente las diferencias observadas entre ambos espacios geográficos. Así mismo, se estudia la estacionalidad y duración de las rutas, las interconexiones internas y con puertos de fuera de los respectivos ámbitos y el tipo de recurso más utilizado por los turistas en las escalas.

Para ello, se emplean principalmente fuentes estadísticas oficiales (WTO, CLIA, ITF, ECC, ACS, F-CCA ${ }^{3}$, etc), datos de las autoridades portuarias, estudios de las principales empresas proveedoras de cruceros, asociaciones internacionales, informes anuales de mercado, material propagandístico y divulgativo, prensa, fotos y cartografía.

En cuanto a la metodología, el análisis se efectúa tanto a nivel cuantitativo, como cualitativo. En el primero de los casos, se analizan los principales componentes del turismo de crucero a partir de variables como número de puertos, destino, buques, pasajeros, duración de los itinerarios y estacionalidad. La tipificación de los puertos se lleva a cabo principalmente a partir de datos cualitativos, con los que se ha establecido la propuesta clasificatoria de los puertos según sus características actuales y las transformaciones recientes. Asimismo, el estudio de los principales recursos visitados se realiza a partir de un análisis de la imagen promocional de cada destino. En este último caso, los datos resultantes deben ser considerados sólo como una aproximación, pues sería interesante contrastar los mismos mediante encuestas. Para ello, podría resultar útil el informe anual de F-CCA, que incluye una completa visión de las actividades turísticas de los pasajeros y su grado de satisfacción, si bien escapa de los objetivos del presente estudio profundizar en este aspecto del análisis.

En primer lugar, se han estudiado los itinerarios que ofrecen las principales compañías de cruceros (Carnival, Royal Caribbean, NCL, Disney, Pullmantur, TUI, AIDA y America Holland) con el fin de poder identificar los puertos y escalas que forman parte de sus rutas habituales. Seguidamente, se realizó un inventario de los principales puertos insulares de cruceros dentro del ámbito de estudio, contando incluso con escalas donde no existen infraestructuras portuarias que permitan el atraque de los buques. En total se analizan 57 puertos y escalas, 48 en el ámbito del Caribe y 9 en la Macaronesia insular europea, aunque también se han considerado parcialmente, dada su importancia, los tres principales puertos continentales de partida de rutas caribeñas: Miami, Fort Lauderdale y Cabo Cañaveral.

Una vez identificados los puertos que conforman el área de estudio, se diseñó una ficha para caracterizar cada una de las escalas, con aspectos que incluyen los tipos de puertos, las características de las infraestructuras portuarias, las transformaciones recientes debidas al turismo de cruceros, la intensidad de usos según el número de cruceros/año, el tipo de recurso turístico que es motivo de atracción turística y las principales actividades desarrolladas por los turistas en cada destino. Asimismo, se estudian las rutas y sus principales características (puertos de embarque, número de escalas, duración, estacionalidad, etc).

Como resultado se obtiene una visión general actualizada del turismo de cruceros en el Caribe y la Macaronesia. Además, ha sido posible realizar un análisis comparado entre estos dos ámbitos, establecer una clasificación de los tipos de puertos de crucero según sus características y efectuar un análisis de los principales recursos territoriales que justifican el producto turístico, advirtiendo que cada vez más, éste se sustenta en el propio itinerario y en los buques.

\section{APROXIMACIÓN AL TURISMO DE CRUCERO EN EL CARIBE}

El origen del turismo de cruceros en el Caribe se remonta a la primera mitad del siglo $\mathrm{XX}$, cuando se desarrolla con la finalidad de facilitar el acceso a te- 
rritorios insulares carentes por entonces de otras posibilidades de conexión (Martí, 1990). El desarrollo de la aviación comercial a comienzos de la segunda mitad del XX benefició, paradójicamente, el desarrollo de la industria de los cruceros al suplir éstos la demanda de aprovechamiento turístico de muchas de las pequeñas islas del Caribe que contaban con líneas regulares marítimas precarias.

Inicialmente, las rutas de cruceros se diseñaban según la ubicación de los recursos territoriales, confeccionando los itinerarios a partir de las ciudades portuarias con mayor encanto turístico (Martí, 1990). Las rutas eran organizadas según la proximidad de las diferentes escalas. En otras palabras, el territorio y sus recursos turísticos, sobre todo los portuarios y urbanos, condicionaban la confección de las rutas de los cruceros. Las navieras clásicas (America Holland, Grace Line y otras) atracaban en La Habana (hasta 1959), San Juan, San José, Cartagena, Aruba, Panamá, Miami y Nueva York, es decir, puertos "tradicionales" que eran utilizados por los cruceros en ruta hacia Sudamérica y desde o hacia Europa.

Con la crisis del petróleo de 1973-74 las grandes compañías como Carnival y Royal Caribbean empezaron a construir buques energéticamente más eficientes y con mayor capacidad de pasaje. Con ello pretendían reducir costes y abrirse a un nuevo perfil de cliente, popularizando así la modalidad turística de cruceros (Rodrigue y Notteboom, 2013). Se produjo un proceso general de modernización, ofreciendo a los turistas un producto más económico y asequible. Se pasó del medio millón de pasajeros registrado para todo el Caribe en 1970, a 3,8 millones en 1980, 7,75 en 1990 y 14,5 en 2000 (ACS, 2016: 3, corregido a partir de CTS statistic ${ }^{4}$ ), habiéndose superado en 2016 los 25 millones de pasajeros de cruceros. El proceso está asociado a las mejoras y modernización de los buques y su incremento en capacidad, tamaño y tonelaje (Tabla 1). Esto ha repercutido en una necesaria y obligada adaptación de los puertos para acoger verdaderos gigantes del mar (Murias, 2002). Barcos como los de la clase Oasis (360 metros de eslora), Quantum (345 m) o Disney Dream y Freedom (340 $m$ ), tienen una capacidad enorme (superando en algún caso los 6000 pasajeros), pero tienen, asimismo, un calado de más de 9 metros, lo que condiciona sus posibilidades de atraque ${ }^{5}$.

La etapa reciente del turismo de crucero se caracteriza por una ampliación y diversificación de la oferta. Ésta ya no se limita a los puertos tradicionales, sino que ahora se crean infraestructuras para uso exclusivo del turismo de crucero. Las nuevas infraestructuras contemplan tanto las de carácter logístico: puertos y embarcaderos, como los servicios en tierra,, llegándose incluso a construir resort y playas artificiales para el desarrollo de las actividades de ocio (Showalter, 1995). Si la motivación principal inicialmente era la visita de diferentes lugares, hoy, en palabras de Palafox (2015: 107) "la clave del éxito de la industria turística de cruceros es que se visualizó como un resort flotante y no como transporte" de manera que "la oferta se ha adaptado a las demandas del turismo, en lugar de mantener la rigidez de la primera etapa."

TABLA 1

EVOLUCIÓN DE LA CAPACIDAD MEDIA DE PASAJEROS EN BUQUES DE CRUCEROS SEGÚN SU AÑO DE CONSTRUCCIÓN (1981-2018)

\begin{tabular}{|c|c|c|c|c|c|c|c|}
\hline $\begin{array}{c}1981- \\
1985\end{array}$ & $\begin{array}{c}1986- \\
1990\end{array}$ & $\begin{array}{c}1991- \\
1995\end{array}$ & $\begin{array}{c}1996- \\
2000\end{array}$ & $\begin{array}{c}2001- \\
2005\end{array}$ & $\begin{array}{c}2006- \\
2010\end{array}$ & $\begin{array}{c}2011- \\
2015\end{array}$ & $\begin{array}{c}2016- \\
2018\end{array}$ \\
\hline 950 & 974 & 1178 & 1556 & 1997 & 2747 & 2893 & 2770 \\
\hline
\end{tabular}

Fuentes: CruiseMapper; Cruisemarketwatch y Whatsinport. Elaboración propia.

El Caribe ha ganado desde 2006 un 13,5\% de capacidad, en cambio, perdió en este mismo periodo un $5,5 \%$ de cuota de mercado (CLIA, 2017) en favor de otros destinos emergentes que crecen a mayor ritmo. En la actualidad, se contabiliza en este espacio geográfico más de medio centenar de puertos entre los de origen (hub) y de escala (port of call), si bien el aprovechamiento es desigual, cuantitativamente hablando. Tres puertos destacan con más de 1.000 cruceros anuales (2018): Cozumel, Nassau y Miami, este último el único con condición de puerto base.

El caso de Cozumel es especialmente significativo, pues su despegue económico y demográfico se ha debido casi en exclusiva al turismo (Palafox, 2015: 110). Con una economía tradicional dedicada a la agricultura de copra, maíz, tabaco y caña de azúcar que perduró hasta la década de 1970, la eclosión del turismo supuso para dicha localidad un salto cuantitativo. Éste se produjo en parte beneficiado por el declive postrevolucionario de Cuba (1959), por entonces principal destino turístico en el Caribe. El turismo de crucero ha situado a Cozumel a la cabeza de los destinos en esta modalidad turística, en competencia año tras año con Bahamas, a la que finalmente ha terminado por desbancar (F-CCA, 2018) 
FIGURA 1

PRINCIPALES ITINERARIOS DE CRUCERO EN EL CARIBE SEGÚN DURACIÓN. SALIDAS DESDE MIAMI

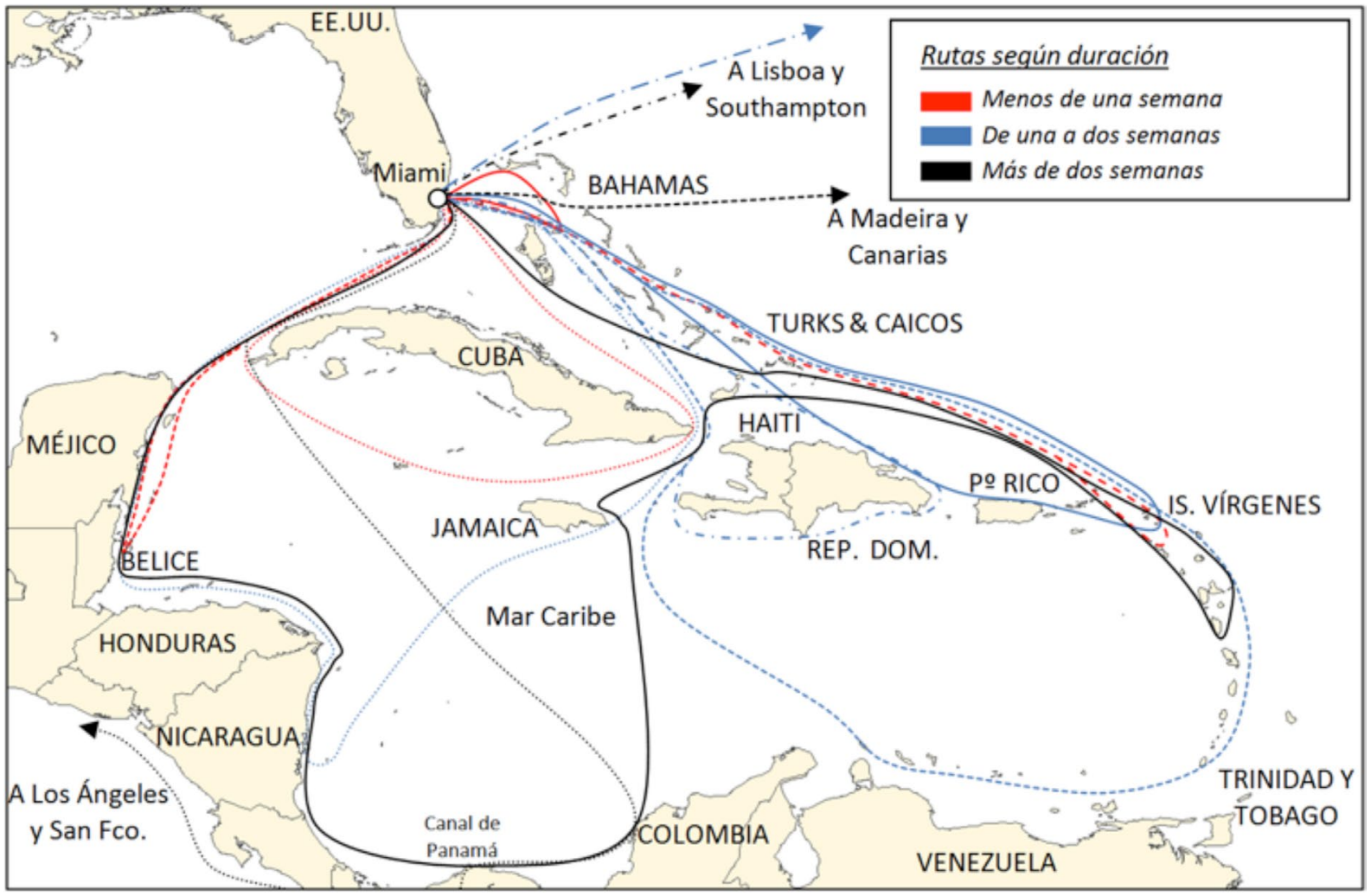

Fuente: Principales líneas de crucero que operan en el Caribe. Cruisetimetables.com. Elaboración propia.

(Figura 2). En 1980, 1996 y 1998, respectivamente, comenzaron a utilizarse tres diferentes muelles para cruceros, con un mínimo de dos posiciones de atraque cada uno (Santander y Ramos, 2011), permitiendo en 2018 un total de 1.420 llegadas. Las inversiones han supuesto una transformación del litoral costero en forma de espacios libres, joyerías, restaurantes y plaza comercial, entre otros servicios (Palafox, 2015).

Pero si un archipiélago se benefició del retraimiento cubano tras el advenimiento del castrismo ese fue Bahamas (Fernández, 2009), y en especial el puerto de Nassau. Al contrario que Freeport que sigue utilizando las instalaciones portuarias comerciales, Nassau ha sabido invertir en un puerto exclusivo para cruceros, lo que le permitió liderar el Caribe en cuanto a número de viajeros hasta 2015 (WTO, 2018). Este destino cuenta además con unas estupendas condiciones naturales de abrigo y la confluencia espacial de un variado tipo de atractivos turísticos. Entre estos se cuentan el centro histórico de Nassau, las compras en Straw Market y Bay Street y la vida nocturna (casinos, cabaret, teatros...) (F-CCA, 2018, vol. 2: 18).
Además, el resort turístico de Paradise Island se encuentra justo al otro lado de la bahía y junto a la terminal de cruceros. Incluye playas, villas de lujo, centros comerciales, oferta de ocio y entretenimiento, campos de golf $\mathrm{y}$ dotaciones portuarias para yates.

Por su parte, San Juan, en Puerto Rico, que llegó a ser el puerto de cruceros más transitado en el Caribe a finales del pasado siglo (César, 1996), ha ido sin embargo perdiendo competitividad desde entonces, descendiendo hasta el séptimo lugar en número de escalas en 2018, por detrás de Gran Caymán, Baseterre (St Kitts \& Nives), Philipsburg-St Maarten y Bridgetown (Barbados), este último un activo hub en rutas transoceánicas.

El caso de Gran Caymán es significativo, pues la alta frecuencia de cruceros en este destino no se debe tanto a la inversión en infraestructuras portuarias, como a la existencia de una oferta complementaria muy potente (principalmente basada en actividades 
FIGURA 2

NÚMERO DE ATRAQUES DE CRUCEROS EN PUERTOS INSULARES DEL CARIBE (2018)

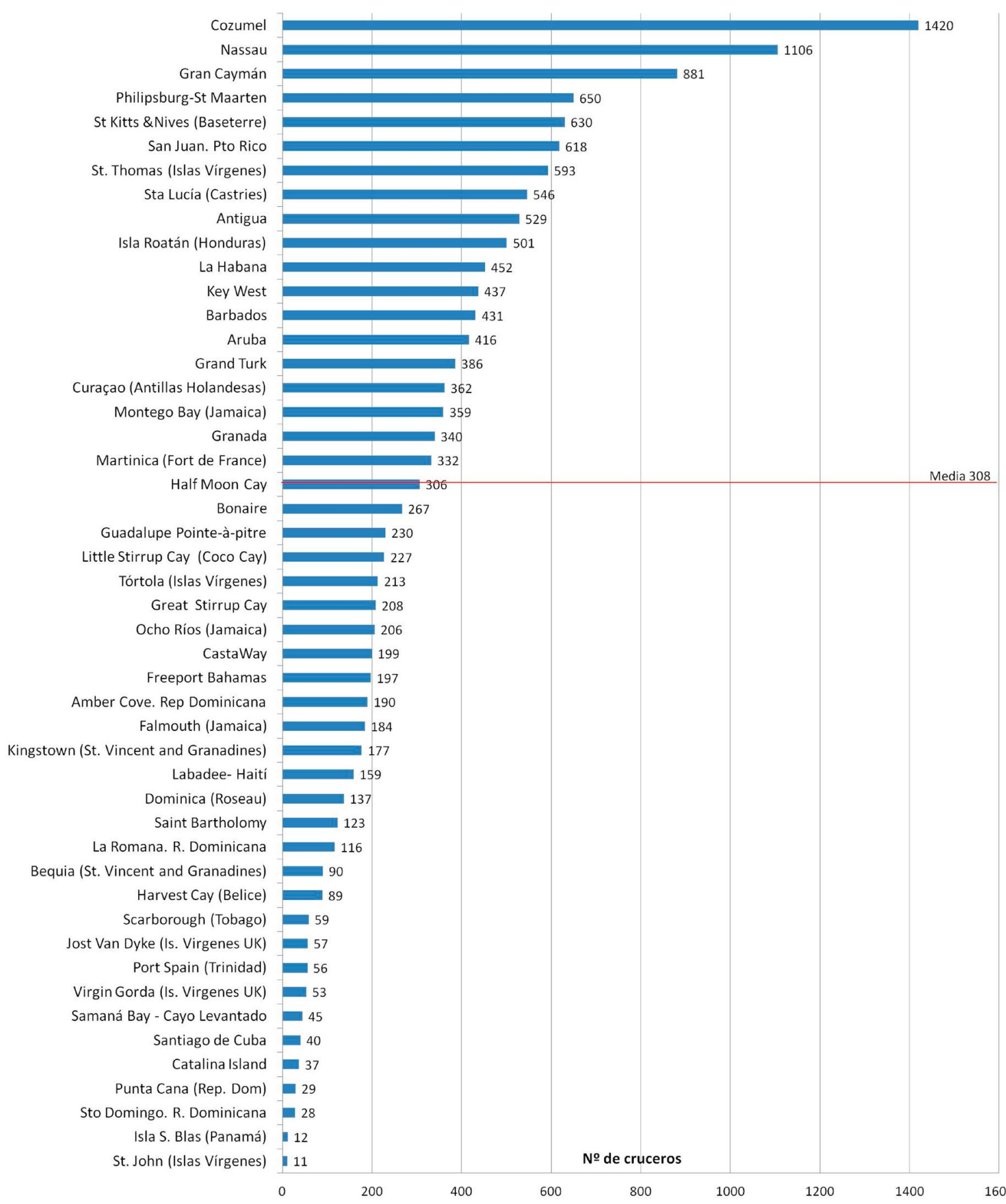

Fuente: Autoridades portuarias respectivas.

náuticas) y a los idílicos paisajes y playas con que cuenta esta isla de tan solo $192 \mathrm{~km}^{2}$.
Los puertos se unen mediante rutas que tienen como punto de partida principal y mayoritario los 
hubs de Florida: Miami, Port Lauderdale y Cabo Cañaveral. Dominan los itinerarios de una semana, que representan el $65 \%$ de los casos, aunque los hay de larga duración, muchos de los cuales se vinculan con el puerto inglés de Southampton, e incluso con viajes de circunvalación. Más adelante se expondrán datos detallados respecto de las rutas de crucero en el Caribe de forma comparada con el ámbito de Macaronesia.

En cuanto a la duración de las escalas, éstas se resuelven en 24 horas o menos en un $96 \%$ de los casos (F-CCA, 2018), aunque las hay también de dos, tres días, o incluso más (desde 7 hasta 11), aspecto este último que suele limitarse a los cruceros de lujo. Destacan los puertos de Bahamas por ser los que acaparan el mayor número de días de atraque, en ocasiones hasta 3 y 4 días en itinerarios de una semana. Las escalas de mayor duración dan idea de una utilización doble de la modalidad del crucero: como tal, pero también como medio de transporte marítimo necesario para luego realizar una actividad turística de sol y playa convencional en tierra. Esta circunstancia es un hecho exclusivo del ámbito del Caribe que no se da en la Macaronesia.

También resulta una novedad la tendencia observada en el Caribe de adquisición en propiedad de pequeños cayos por parte de las principales líneas de cruceros (Royal Caribbean, NCL, Disney, CarnivalPrincess). En estos destinos se desarrolla una actividad mixta de crucerismo y estancia. La escala se crea con una potente inversión que supone la transformación de este espacio, donde se construyen residencias, embarcaderos, playas artificiales y toda una oferta complementaria para el desarrollo de la actividad turística de sol y playa.

Islas como Great Stirrup Cay, adquirida en 1979 por Norwegian Cruise Line (Showalter, 1995), pero desarrollada como resort hace menos de 10 años, fue pionera en este tipo de actuaciones. Los manglares que ocupan de manera natural la isla son paulatinamente sustituidos por espacios para el ocio e incluso se modifica la topografía y el litoral (Kester, 2002). Hay otros ejemplos, todos de ejecución muy reciente: Little Stirrup Cay (promocionado como Cayo Coco), está a menos de $1 \mathrm{~km}$ de distancia de Great Stirrup, pero pertenece a la competencia (Royal Caribbean). También en Bahamas se encuentra Half Moon Cay, de America Holland, y Castaway Cay (Disney). En Belice, donde las condiciones del litoral y la falta de inversiones dificultan la llegada de los cruceros, recientemente el gobierno ha alcanzado un acuerdo con NCL para desarrollar en Harvest Cay un resort de similares características. La transformación, que incluye residencias, playas e incluso canales artificiales, ha afectado al $80 \%$ de la superficie de esta isla de tan sólo $0,3 \mathrm{~km}^{2}$, donde la naviera promociona un destino con estancias en tierra que más se parecen al turismo convencional de litoral que a la modalidad de cruceros $^{6}$. Otra escala parecida es Princess Cay (de Carnival), que si bien no ocupa la totalidad del cayo, sí responde al mismo modelo: resort turístico aislado al que acuden los cruceristas. Lo mismo se puede decir de Labadee (Haití), un puerto privado de Royal Caribbean que cuenta con un recinto vallado para uso exclusivo de los turistas de crucero.

Ante esta nueva tendencia de mercado cabe reformular los tradicionales planteamientos respecto a la utilización del territorio por parte del turismo de cruceros. Si hasta ahora las rutas y por tanto el aprovechamiento espacial se justificaban por la existencia de recursos que constituían el atractivo o hinterland turístico, desde hace unos años se desarrolla una modalidad híbrida de turismo en la que se combina la esencia del crucero con las actividades propias del sol y playa. En este sentido, coincidimos plenamente con Palafox (2015).

Este distanciamiento del espacio geográfico es algo ya constatado por Cunin (2006: 11), cuando en relación a las promociones realizadas para los cruceros en el Caribe observaba con asombro la "escasa referencia a los lugares visitados y la insistencia en las características propias del barco" que se convierte así en el principal reclamo.

Respecto a las actividades turísticas que los visitantes desempeñan cuando hacen escala, el $74 \%$ de los pasajeros de cruceros en ruta por el Caribe adquieren excursiones en el barco (Honey, 2017: 10; F-CCA, 2018) en lugar de realizar por su cuenta actividades de ocio en las playas. Esto supone ampliar el ámbito de utilización de los recursos territoriales más allá del entorno inmediato del puerto, si bien los circuitos suelen quedar limitados a visitas cortas de media jornada dado que muchos pasajeros viajan en modalidad de todo incluido y desean volver al buque para la hora de la comida (F-CAA, 2018).

Las compras constituyen una de las actividades más demandadas, en cuyo caso sí que suele limitarse el radio de acción próximo al desembarco. Algunos de los centros de compras más frecuentados son Straw Market y Bay Street (Nassau); Taj-Mahal y Ocean Village (Ocho Ríos); Royal Village (Cozumel); las áreas 
especializadas de Cayman Craft Market, Old Havana y Rockys Diamond (Gran Cayman), o incluso zonas de compras cercanas a los puertos de Florida como Byscaine Boulevard, Lincoln Road Mall y Cocowalk (Miami) y Harbor Shops y Beach Place (Fort Lauderdale)..

\section{APROXIMACIÓN AL TURISMO DE CRUCEROS EN LA MACARONESIA INSULAR EUROPEA}

El turismo de cruceros en el ámbito de los archipiélagos atlánticos de Azores, Madeira y Canarias está asociado a las grandes rutas trasatlánticas de mediados del siglo XX, resultando su desarrollo muy posterior al acontecido en el Caribe. Durante esta fase inicial, coincidente con el despegue del turismo de masas en estas islas, con frecuencia los grandes buques hacían escala en sus puertos. Sin embargo, era un período de escaso movimiento turístico general si se compara con los registros actuales.

Aunque diversos trasatlánticos de la Cunard Line como el Queen Mary y el Queen Elizabeth llegaron a las islas en la década de 1960, la mayor parte de viajeros por vía marítima procedían de líneas regulares y decayeron con rapidez a medida que se desarrollaron y abarataron los transportes aéreos y aumentó la oferta hotelera en tierra. Este hecho supuso una fractura en la evolución del crucerismo en este ámbito del Atlántico, todo lo contrario de lo que aconteció en el Caribe en similares circunstancias.

La recalada de los buques estaba supeditada al desarrollo de las infraestructuras portuarias, pues resultaba esencial dotar a los puertos de espacios de atraque y abrigo con calado suficiente para este tipo de barcos. En el caso de Funchal, las mejoras se llevaron a cabo en la etapa de 1939-1979 (González y Ramón, 2017), en fechas casi coincidentes con los desarrollos experimentados en el puerto de Las Palmas dentro de la fase que hemos denominado de consolidación (1937-1970) (Martín, 2001; Ramón y González, 2017). Esta fase supuso la ampliación del dique exterior y, con esta obra, conseguir zona de atraque habilitada para los cruceros trasatlánticos. En otros puertos de las islas peor dotados los cruceros únicamente podían anclar cerca de la costa y el pasaje debía descender mediante barcazas.

Sin embargo, desde finales del siglo XX se ha producido un desarrollo notable de los puertos canarios, madeirense y azorianos, con mejoras portuarias que permiten el atraque de los cruceros, como ya ocurre en Santa Cruz de Tenerife, La Palma, Arrecife y Puerto del Rosario (Canarias), Punta Delgada, Praia da Victoria y Horta (Azores) y los antes citados de Las Palmas de Gran Canaria y Funchal. En cambio, otros puertos menores e insuficientemente dotados continúan ofreciendo únicamente una bahía abrigada para el anclaje o el atraque sólo de buques pequeños ( $\mathrm{La}$ Gomera y El Hierro, en Canarias y Porto Santo, en Madeira).

En los últimos 20 años los principales puertos han habilitado espacios para el turismo de cruceros, destacando en este sentido Las Palmas (hoy con una terminal para atracar cinco buques y propuesta de arrendamiento de una nueva terminal privada), Funchal (con capacidad para tres), y Santa Cruz de Tenerife y Punta Delgada, que han inaugurado recientemente sus respectivas terminales de crucero, con 400 metros de línea de atraque en el caso de Santa Cruz y 380 en el de Punta Delgada, e inversiones que rondan los 50 millones de euros en cada caso (Archivos de la Autoridad Portuaria. Puertos de Las Palmas, Santa Cruz de Tenerife y Madeira).

El volumen de turistas llegados mediante cruceros ha ido creciendo a lo largo del siglo XX. A día de hoy, los puertos más visitados son los de Santa Cruz de Tenerife, Las Palmas de Gran Canaria y Funchal (Tabla 2). Hay que tener en cuenta que Las Palmas se ha convertido en puerto de partida y, en este sentido, el impacto económico de esta actividad sobre la ciudad decrece, pues los turistas son trasladados directamente desde el aeropuerto al embarque.

El número anual de escalas en 2018 para los puertos macaronésicos suma 1955 , lo que da una media de 198 por destino, muy lejos de las 305,6 del Caribe. Cuatro puertos se sitúan por encima de la media, acumulando el $72,7 \%$ de los atraques (Figura 3). Estos son: Santa Cruz de Tenerife, Funchal, Arrecife y Las Palmas de Gran Canaria. Estos datos reflejan una equiparación entre las infraestructuras portuarias y la inversión en servicios, pues los puertos más visitados han efectuado mejoras relacionadas con el turismo de cruceros en los últimos 15 años. La excepción es Punta Delgada, que aun habiendo invertido más de 50 millones, procedentes en buena parte de fondos de cohesión, no ha visto un rendimiento que permita equipararle a los otros puertos principales del ámbito analizado. Por otra parte, Santa Cruz de La Palma (con 185 escalas) planifica un crecimiento de su línea de atraque de cruceros para 2021 (actualmente en fase de anteproyecto), lo que le permitiría incrementar la frecuencia de estos buques en su puerto. 
TABLA 2

ESCALAS Y PASAJEROS DE CRUCEROS EN LOS PRINCIPALES PUERTOS DE LA MACARONESIA EUROPEA (2000-2016)

\begin{tabular}{|c|c|c|c|c|c|c|c|c|c|c|c|c|c|c|}
\hline Año & Punta Delgada & \multicolumn{2}{|c|}{ Funchal } & \multicolumn{2}{c|}{ S/C La Palma } & \multicolumn{2}{c|}{ S/C Tenerife } & \multicolumn{2}{|c|}{ Las Palmas } & \multicolumn{2}{c|}{ Fuerteventura } & \multicolumn{2}{c|}{ Arrecife } \\
\hline & Esc. & Pas. & Esc. & Pas. & Esc. & Pas. & Esc. & Pas. & Esc. & Pas. & Esc. & Pas. & Esc. & Pas. \\
\hline 2000 & & & & & 47 & 34122 & 168 & 125664 & 107 & 80803 & 5 & 1915 & 103 & 65815 \\
\hline 2001 & & & & & 66 & 50160 & 199 & 159598 & 111 & 87934 & 9 & 2016 & 127 & 96780 \\
\hline 2002 & & & & & 102 & 81887 & 209 & 180128 & 131 & 108360 & 24 & 17762 & 161 & 138859 \\
\hline 2003 & & & & & 111 & 98583 & 232 & 231432 & 143 & 123087 & 37 & 36385 & 179 & 169504 \\
\hline 2004 & & & & & 104 & 111434 & 228 & 327863 & 150 & 146350 & 39 & 34697 & 185 & 212283 \\
\hline 2005 & & & & & 113 & 123334 & 236 & 372260 & 144 & 149010 & 38 & 45066 & 172 & 205957 \\
\hline 2006 & & & & & 97 & 112475 & 207 & 313861 & 124 & 125268 & 39 & 47817 & 145 & 148477 \\
\hline 2007 & & & & & 123 & 148710 & 217 & 358738 & 147 & 165764 & 39 & 49002 & 167 & 205881 \\
\hline 2008 & & 37973 & & 394960 & 90 & 143764 & 219 & 402018 & 147 & 235093 & 34 & 63421 & 172 & 255784 \\
\hline 2009 & & & & & 97 & 140175 & 218 & 420967 & 151 & 252751 & 37 & 67881 & 199 & 302135 \\
\hline 2010 & - & - & - & - & 115 & 186558 & 253 & 536331 & 167 & 296082 & 36 & 74663 & 178 & 299989 \\
\hline 2011 & 42 & 78609 & 303 & 540180 & 122 & 182872 & 283 & 608979 & 197 & 418184 & 44 & 87274 & 172 & 261937 \\
\hline 2012 & 120 & 86942 & 336 & 592935 & 138 & 183316 & 318 & 667717 & 221 & 420985 & 45 & 86262 & 204 & 327972 \\
\hline 2013 & 92 & 73102 & 286 & 475826 & 144 & 206877 & 289 & 527896 & 210 & 425235 & 51 & 85371 & 203 & 340120 \\
\hline 2014 & 90 & 78802 & 283 & 475955 & 148 & 229940 & 298 & 544893 & 229 & 587153 & 71 & 117748 & 212 & 355066 \\
\hline 2015 & 137 & 104255 & 308 & 578492 & - & 206799 & 506 & 933161 & 243 & 613156 & 65 & 111297 & 216 & 377803 \\
\hline 2016 & 121 & 97044 & - & 520168 & - & 224432 & - & 883339 & 237 & 639015 & 93 & 172247 & 224 & 422159 \\
\hline
\end{tabular}

Fuente: Autoridades portuarias respectivas.

FIGURA 3

NÚMERO DE ATRAQUES DE CRUCEROS EN PUERTOS INSULARES DE LA MACARONESIA EUROPEA (2018)

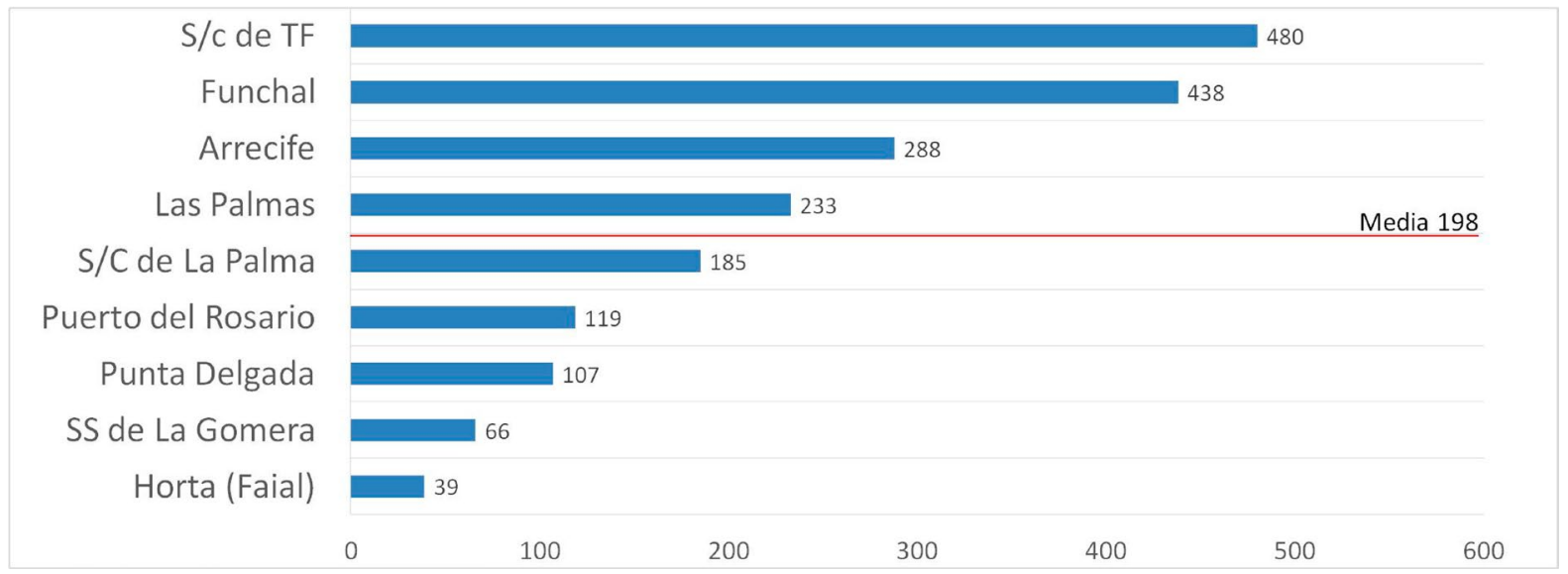

Fuente: Autoridades portuarias respectivas.

Las rutas tienen como punto de partida Gran Canaria $(21,2 \%)$, Southampton $(18,3 \%)$, Tenerife $(12,2 \%)$ y Barcelona $(10,2 \%)$, como principales puertos, además de otros del Mediterráneo Occidental (Civitavecchia, 4,8\%; Génova, 4,1\%; Marsella, $4 \%$ y Savona, $1,9 \%$ ) y también del Caribe (Fort Lauderdale, 2,6\%; Miami, $1,7 \%$ y Bridgetown, Barbados, 1,5\%) (Figura 4).

La duración de las escalas es abrumadoramente inferior a las 24 horas, dedicando el tiempo en tierra 
FIGURA 4

PRINCIPALES ITINERARIOS DE CRUCERO EN EL ATLÁNTICO MEDIO SEPTENTRIONAL ORIENTAL

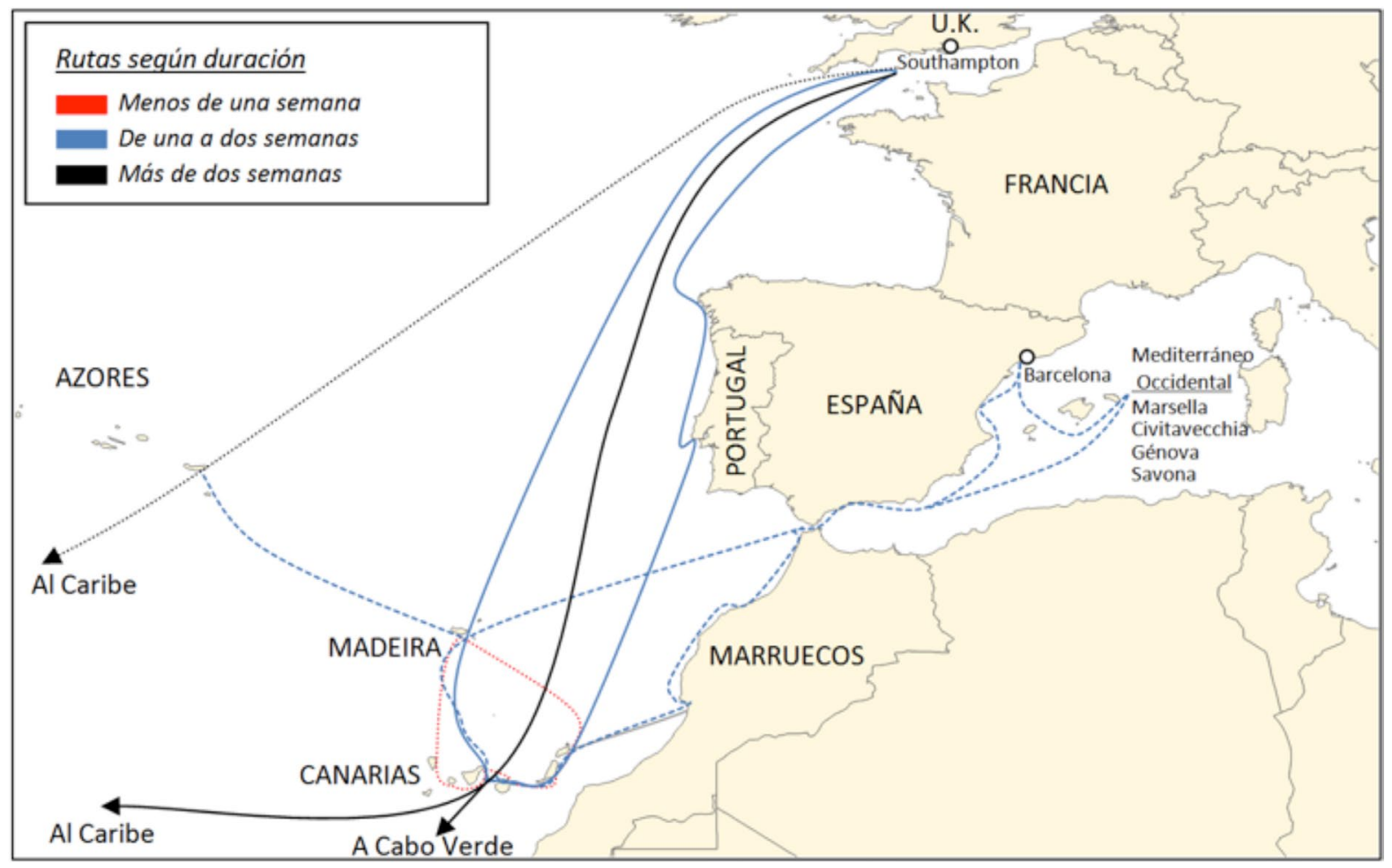

Fuente: Realizado a partir de datos de las respectivas autoridades portuarias. Elaboración propia.

sobre todo a visitar la ciudad (EDEI, 2016). En este sentido, y como más adelante se abordará con mayor detalle, existe una cierta similitud entre los dos ámbitos considerados, si bien la duración de las escalas es más baja en la Macaronesia que en el Caribe.

\section{Puertos e itinerarios de CRUCEROS EN EL ATLÁNTICO MEDIO SEPTENTRIONAL. VISIÓN COMPARADA ENTRE El CARIBE Y LA MACARONESIA}

Cuantitativamente, los espacios considerados de Caribe y Macaronesia están muy distanciados, como corresponde a un destino consolidado frente a otro en pleno desarrollo. Si bien los dos están creciendo, aunque a distinto ritmo, no son espacios que se aproximen, ni en el número de puertos, ni en tamaño, ni por supuesto en valores totales de rutas, buques y pasajeros. Mientras que el Caribe supera los 25 millones de turistas anuales (dato para 2016), Macaronesia ronda los 1,2 millones ese mismo año. Las escalas en 2018 también están muy distantes: 14.813 en el caso del Caribe, por las 1.955 de Macaronesia.
Tampoco se asemejan las magnitudes geográficas y poblacionales, pues mientras el ámbito insular del Caribe suma $191.895 \mathrm{~km}^{2}$ y una población aproximada de 32.373.000 habitantes, la Macaronesia insular europea cubre una superficie de $10.626 \mathrm{~km}^{2}$ y tiene una población de 2.616.500 habitantes.

En cuanto a los puertos base, Miami, Port Lauderdale y Cabo Cañaveral representan más de las tres cuartas partes de las salidas de las rutas por el Caribe, lo que debe ser achacado principalmente a la importancia y proximidad del mercado norteamericano (Rodrigue y Notteboom, 2013: 38). Los puertos insulares, como San Juan (Puerto Rico), Montego Bay (Jamaica) y La Habana (Tabla 3), sólo representan un $14 \%$. Por el contrario, en la Macaronesia los puertos de Santa Cruz de Tenerife y Las Palmas de Gran Canaria son puerto base de un $33 \%$ de rutas que tienen lugar en este ámbito. A este respecto, los puertos insulares macaronésicos tienen un mayor peso como punto de partida de los cruceros que los del Caribe, combinándose siempre con traslados aéreos.

Un hecho relevante que resulta del análisis de los puertos de partida y de las rutas de los cruceros es 
que el archipiélago de Azores no forma parte, en este aspecto, del ámbito de la Macaronesia, sino que constituye recalada de itinerarios transoceánicos. Esto se pone de manifiesto al comprobar que está principalmente conectado con puertos de ambas orillas del Atlántico medio septentrional, como Southampton, Fort lauderdale, Barbados y Miami, y no con puertos macaronésicos, o tan siquiera con Lisboa. En este sentido, le pasa lo mismo a los puertos de Bermudas, en especial King Wharf, referente en las rutas transoceánicas y asociado al turismo estacional de estados norteños de la costa atlántica estadounidense, con la que tiene una especial vinculación (Nueva York y Halifax, principalmente).

En cuanto a la tipología portuaria, se ha llevado a cabo un estudio de las características de los puertos y escalas insulares en relación a su adaptación para el turismo de cruceros, lo que ha permitido establecer la siguiente clasificación:

A) Puertos exclusivos de cruceros donde existen terminales especializadas. Podrán ser de 3 tipos:

1. Rehabilitados a partir de antiguas infraestructuras portuarias obsoletas (se sitúan en un entorno portuario y forman parte de un puerto mixto de carácter comercial e industrial). Este es el caso de los puertos de La Habana, Santo Domingo, Martinica (terminal Tourelles), Port Spain (Trinidad), Las Palmas, Santa Cruz de Tenerife y Punta Delgada.

2. Construidos ex profeso para cruceros o pasaje como rehabilitación-ampliación de un puerto ya existente: Montego Bay, Bridgestown, St. Marteen, Tórtola, Gran Caimán, Barbados, Aruba, Martinica (terminal Pointe Simon), Guadalupe, St. Thomas (Islas Vírgenes), Scarborough (Tobago), San Juan, Nassau, Key West, Puerto del Rosario, Arrecife y Funchal.

3. Construidos ex profeso como nueva infraestructura portuaria, su emplazamiento es aislado, no se encuentra integrado en otro puerto. Es un caso muy común, pero exclusivo del ámbito caribeño: Curaçao, La Romana, Granada, Dominica, Santa Lucía, St. Kitts \& Nives, Isla Margarita, Cozumel, Ocho Ríos, Antigua, Isla Roatán, Amber Cover (Rep. Dominicana), Bonaire, Grand Turk, Falmouth y Labadee (Haití) y Castaway. Estos dos últimos constituyen casos singulares, pues ambos se corresponden con infraestructuras portuarias aisladas y exclusivas de cruceros, vinculadas a un resort turístico del que forman parte y al que dan servicio.

PRINCIPALES PUERTOS DE PARTIDA SEGÚN ÁMBITO (2018)

\begin{tabular}{|l|c|c|}
\hline \multicolumn{1}{|c|}{ Puerto } & Salidas & $\%$ \\
\hline Miami & 966 & 31,9 \\
\hline Fort Lauderdale & 701 & 23,2 \\
\hline Cabo Cañaveral & 558 & 18,4 \\
\hline San Juan (Po Rico) & 193 & 6,4 \\
\hline La Habana & 149 & 4,9 \\
\hline NYC & 145 & 4,8 \\
\hline Jacksonville & 79 & 2,6 \\
\hline Cozumel & 71 & 2,3 \\
\hline Montego Bay & 61 & 2,0 \\
\hline Southsampton & 52 & 1,7 \\
\hline San Diego & 15 & 0,5 \\
\hline Lisboa & 12 & 0,4 \\
\hline San Francisco & 11 & 0,4 \\
\hline Boston & 11 & 0,4 \\
\hline
\end{tabular}

\begin{tabular}{|l|c|c|}
\hline \multicolumn{3}{|c|}{ MACARONESIA } \\
\hline Puerto & Salidas & $\%$ \\
\hline Gran Canaria & 319 & 21,2 \\
\hline Southampton & 276 & 18,3 \\
\hline Tenerife & 184 & 12,2 \\
\hline Barcelona & 153 & 10,2 \\
\hline Civitavecchia & 72 & 4,8 \\
\hline Génova & 62 & 4,1 \\
\hline Marsella & 60 & 4 \\
\hline Fort Lauderdale & 39 & 2,6 \\
\hline Lisboa & 37 & 2,5 \\
\hline Savona & 29 & 1,9 \\
\hline Miami & 25 & 1,7 \\
\hline Barbados (Bridgetown) & 22 & 1,5 \\
\hline Londres & 17 & 0,9 \\
\hline Amsterdam & 14 & \\
\hline
\end{tabular}

Fuente: Autoridades portuarias. Elaboración propia.

* Sombreados los puertos internos de los respectivos ámbitos considerados. 
B) Puertos mixtos (usos compartidos) donde no existe una terminal exclusiva para cruceros. Es el caso de escalas "poco desarrolladas" como Cienfuegos y Santiago de Cuba, Freeport, Horta, Santa Cruz de La Palma y La Gomera.

C) Escalas de anclaje donde no existe medio para el atraque, distinguiéndose los siguientes tipos, todos ellos exclusivos del ámbito del Caribe:

1. Con puerto que no reúne condiciones para el atraque de los cruceros, pero dispone de embarcadero o pantalán para embarcaciones menores. Es el caso de Port Elizabeth, St. John y Spanish Town (Virgin Gorda).

2. Con embarcadero o pantalán para embarcaciones menores. Es un caso muy común, especialmente cuando los fondos someros no permiten aproximarse a los buques de mayor calado. Es la solución adoptada para las recaladas en islas privadas propiedad de grandes líneas de crucero, como Great Stirrup Cay, Little Stirrup Cay (Cayo Coco), Half Moon Cay, Princess Cay y Harvest Bay, además de otras escalas como Jost Van Dyke (Is. Vírgenes Británicas), St. Barthélemy (Antillas Holandesas), Cayo levantado (Rep. Dominicana) y Portsmouth (Dominica).

3. Sin infraestructura para desembarque. pequeños islotes vírgenes que se inician como escala turística, poco transformados, donde no existe infraestructura alguna, tipo embarcadero, pantalán o similar, caso de San Blas e Isla Catalina (Rep. Dominicana).

Por último, en lo referente a los tipos de atractivos turísticos más demandados, existe una tendencia clara por parte de los turistas a realizar visitas generales, tanto de índole urbana, la mayoría, como recorridos extraurbanos. En este último caso se trata de excursiones donde se contemplan los paisajes insulares de camino en ocasiones a un atractivo turístico concreto, normalmente un espacio protegido: Timanfaya, Teide, Betancuria o Taburiente, en Canarias; San Miguel, Furnas y Sete Cidades, en Azores; Câmara do Lobos (Madeira); Sierra Maestra y Gran Piedra, (Cuba); Lucayan, (Freeport); Río Camuy y Cabezas de San Juan (Puerto Rico); Virgin Island N.P. (St. John); Trois Pitons (Dominica); Mont Pelé y Le Diamanti (Martinica); Harrison's Cave y Farley Hill (Barbados); Christoffelpark, Arikok y Slagbaai (Antillas Holandesas); Brimstone (St. Kitts \& Nives); Laguna de la Restinga (Antigua); Chakanaab (Cozumel), Hell (Gran Caymán), etc.
El predominio de las visitas urbanas es común a los dos ámbitos considerados.

Además de pasear, las actividades que más realizan los turistas de crucero son las compras, buceo, playa y snorkel. En el caso del Caribe existe cierto equilibrio entre escalas "urbanas" (24 de 48), playas y resort turísticos (15 de 48) y carácter mixto u otros (9 de 48). Por el contrario, en Macaronesia todas las escalas tienen como principal recurso turístico la ciudad próxima. Quizás las excepciones las hallemos en Lanzarote (el parque nacional de Timanfaya es la principal atracción); Ponta Delgada (se visitan los Lagos de Sete Cidades y las Furnas) y Fuerteventura (donde se realizan excursiones a Betancuria).

En cualquier caso y como cabría esperar, los atractivos visitados son siempre lugares próximos al puerto, incluso cuando se sale de la ciudad, pues las excursiones, programadas o no, se deben resolver en el escaso tiempo que dura la escala y ésta es, en más del $95 \%$ de los casos, de un solo día. Este aspecto es común a los dos ámbitos considerados, con la excepción de lo que hemos denominado destinos de estancia, en los que se combina la modalidad de crucero con el hospedaje en resort turísticos.

Finalmente, en relación a las rutas, del Caribe podría decirse que es un destino más local y cerrado, donde predominan los programas cortos de menos de 7 días, pues éstos representan dos de cada tres cruceros (65,15\%); mientras que en Macaronesia tan sólo el $31,75 \%$ de los itinerarios son de una semana, dominando por el contrario las rutas de entre 8 y 15 días (40,2\%), algo que está directamente relacionado con la cercanía o lejanía de los mercados y de las propias escalas (Tabla 4). De nuevo Azores manifiesta particularidades también en este aspecto, pues debido a su aislamiento y a la distancia que separa al archipiélago de los principales puertos de partida de los cruceros, predominan las rutas de entre 16 y 28 días de duración, algo que no sucede en ningún otro de los puertos analizados. Este dato también se refleja en la temporalidad de Punta Delgada, donde casi el $40 \%$ de las escalas se produce en abril, como resultado del traslado de buques entre los mares Caribe y Mediterráneo a causa del cambio de temporada en uno y otro destino (Esteve-Pérez et al, 2015), aspecto vinculado con la estacionalidad de esta modalidad turística.

En este sentido, la estacionalidad es parecida (Figura 5) aunque no homogénea para todos los puertos. Analizada por ámbitos se observa que es aún 
TABLA 4 DURACIÓN DE LAS RUTAS DE CRUCEROS SEGÚN ÁMBITO

\begin{tabular}{|l|c|c|c|c|}
\hline \multicolumn{1}{|c|}{ Ámbito } & $\begin{array}{c}\text { De } \\
\mathbf{1} \text { a } \mathbf{7} \text { días }\end{array}$ & $\begin{array}{c}\text { De } \\
\mathbf{8} \text { a } \mathbf{1 5}\end{array}$ & $\begin{array}{c}\text { De } \\
\mathbf{1 6} \text { a } \mathbf{2 8}\end{array}$ & Más de 28 \\
\hline Caribe $^{*}$ & $65,15 \%$ & $26,88 \%$ & $6,5 \%$ & $1,47 \%$ \\
\hline Macaronesia & $31,75 \%$ & $40,16 \%$ & $21,58 \%$ & $6,53 \%$ \\
\hline $\begin{array}{l}\text { Canarias- } \\
\text { Madeira }\end{array}$ & $34,6 \%$ & $40,98 \%$ & $18,94 \%$ & $5,48 \%$ \\
\hline Azores & $0 \%$ & $31,1 \%$ & $50,78 \%$ & $18,11 \%$ \\
\hline
\end{tabular}

Fuente: Autoridades portuarias respectivas. Estimación realizada a partir de los datos referidos a los 10 puertos con mayor volumen de cruceros en 2018: Nassau, Cozumel, Gran Caimán, Philisburg (St. Marteen), Baseterre (St. Kitts), Bridgetown (Barbados), San Juan Po Rico, St. Thomas, Santa Lucía y Antigua.

más acusada en Macaronesia que en el Caribe, aunque existe en ambos casos una marcada temporada alta invernal (de octubre a abril). Para este análisis se ha realizado un cálculo sencillo basado en el índice de Gini aplicado al número de cruceros mensuales, de donde se obtiene la medida de la estacionalidad (Tabla 5).

El índice de Gini es uno de los métodos de análisis de frecuencia más comúnmente aceptado (Fernández-Morales y Cisneros-Martínez, 2019), frente a otras posibilidades, como podría ser la desviación estándar, o el índice de Theil (Sainaghi, Mauri y d’Angella, 2019).
El índice de Gini ofrece una valoración de la estacionalidad (o concentración de la actividad) cuyo valor se sitúa entre 0 y 1 . Cuanto menor sea dicho índice, mayor será la distribución equitativa de los cruceros entre los 12 meses del año. En este sentido, los valores quedan establecidos entre 0,07 (La Habana), el valor más bajo e indicativo de una frecuencia de cruceros más homogénea durante todo el año, y el valor máximo $(0,84)$, que evidencia un fuerte contraste entre temporada alta y temporada baja. Este máximo valor se obtiene en el puerto de Antigua. Los meses de mayo a junio son de muy escasa actividad, con más de una quincena de puertos que no tienen escala alguna durante este período. En parte esto es debido a la competencia de otros destinos en los meses de verano, especialmente del Mediterráneo, cuya temporada alta estival coincide con los valles de actividad en Caribe, pero sobre todo en Macaronesia, que se ve más afectada por este motivo (Esteve-Pérez et al, 2015). La media general para ambos ámbitos geográficos es de 0,45, resultando mayor para Macaronesia $(0,5)$, que para el Caribe $(0,4)$.

En resumen, en cuanto a la actividad de cruceros en el Atlántico medio septentrional, análisis de sus puertos y escalas, recursos turísticos visitados y características de las rutas, se puede afirmar que existen similitudes, pero sobre todo diferencias, cuando se comparan ambas orillas, el Caribe y la Macaronesia. Un resumen comparativo se expone en la tabla 6:

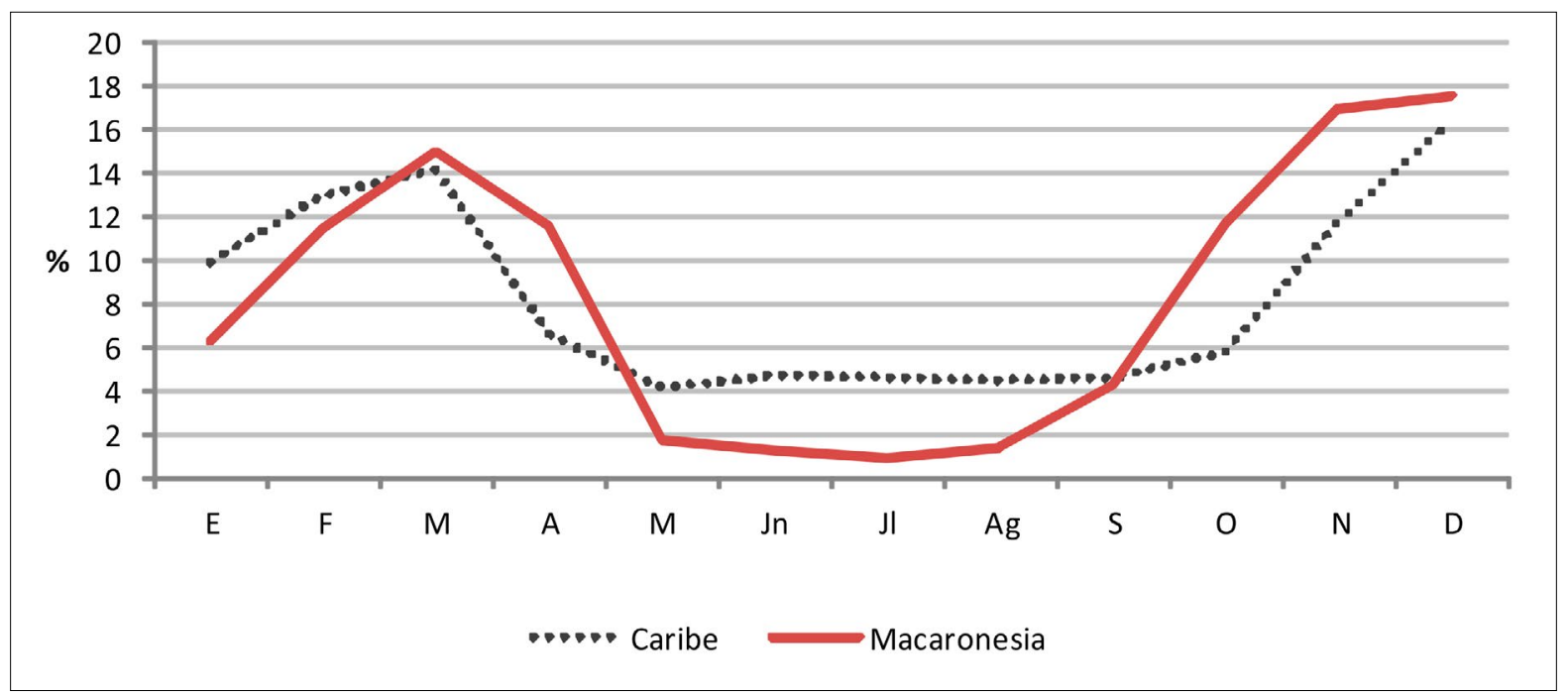

Fuente: Autoridades portuarias. Elaboración propia. 
TABLA 5

ÍNDICE DE ESTACIONALIDAD (ÍNDICE DE GINI) SEGÚN NÚMERO DE ATRAQUES MENSUALES POR PUERTOS Y ÁMBITOS GEOGRÁFICOS (2018)

\begin{tabular}{|c|c|c|c|c|c|}
\hline Puerto & IE & Puerto & IE & Puerto & IE \\
\hline La Habana & 0,07 & Falmouth (Jamaica) & 0,33 & Antigua & 0,57 \\
\hline Nassau & 0,11 & Aruba & 0,34 & La Romana. Rep Dominicana & 0,58 \\
\hline Freeport Bahamas & 0,12 & Amber Cove. Rep Dominicana & 0,35 & Punta Delgada & 0,61 \\
\hline Great Stirrup Cay & 0,13 & Santiago de Cuba & 0,37 & $\begin{array}{l}\text { Samaná Bay - Cayo Levantado (Rep. } \\
\text { Dom) }\end{array}$ & 0,62 \\
\hline Little Stirrup Cay (Coco Cay) & 0,15 & Bonaire & 0,38 & Granada & 0,62 \\
\hline Isla Roatán (Honduras) & 0,17 & Cuba-Cienfuegos & 0,43 & Sto Domingo. Rep Dominicana & 0,64 \\
\hline Cozumel & 0,18 & Horta (Faial) & 0,43 & Dominica (Roseau) & 0,64 \\
\hline CastaWay & 0,19 & St Kitts \&Nives (Baseterre) & 0,44 & $\begin{array}{l}\text { Kingstown (St. Vincent and } \\
\text { Granadines) }\end{array}$ & 0,65 \\
\hline Grand Turk & 0,20 & Harvest Cay (Belice) & 0,45 & Martinica (Fort de France) & 0,67 \\
\hline Labadee- Haití & 0,21 & Funchal & 0,45 & Guadalupe Pointe-à-pitre & 0,69 \\
\hline Key West & 0,23 & Sta Lucía (Castries) & 0,46 & Port Spain (Trinidad) & 0,69 \\
\hline Half Moon Cay & 0,24 & Arrecife & 0,47 & Catalina Island. Rep Dominicana & 0,71 \\
\hline San Juan. Pto Rico & 0,24 & S/c de TF & 0,47 & Bequia (St. Vincent and Granadines) & 0,73 \\
\hline Gran Caymán & 0,24 & Punta Cana, Rep. Dominicana & 0,49 & Saint Bartholomy & 0,73 \\
\hline St. Thomas (Islas Vírgenes) & 0,25 & Barbados & 0,49 & Scarborough (Tobago) & 0,74 \\
\hline Bahamas Princess Cay & 0,28 & Puerto del Rosario & 0,52 & Virgin Gorda (Is. Virgenes UK) & 0,79 \\
\hline Montego Bay (Jamaica) & 0,30 & SS de La Gomera & 0,52 & Jost Van Dyke (Is. Virgenes UK) & 0,79 \\
\hline Curaçao (Antillas Holandesas) & 0,31 & S/C de La Palma & 0,52 & Isla S. Blas (sólo anclaje) Panamá & 0,79 \\
\hline Philipsburg-St Maarten & 0,33 & Las Palmas & 0,55 & St. John (Islas Vírgenes) & 0,83 \\
\hline Ocho Ríos (Jamaica) & 0,33 & Tórtola (Islas Vírgenes) & 0,56 & Antigua-Faltmouth & 0,84 \\
\hline TOTAL CARIBE & 0.44 & TOTAL MACARONESIA & 0.50 & TOTAL (ambos ámbitos) & 0.45 \\
\hline
\end{tabular}

Índice de estacionalidad (IE) calculado a partir del Índice de Gini respecto al porcentaje mensual de cruceros.

Fuente: Autoridades portuarias. Elaboración propia.

\section{CONCLUSIONES}

Asistimos a una transformación del modelo de turismo de cruceros que es resultado del crecimiento de este segmento, lo que está dando lugar a nuevas formas de utilización del territorio y sus recursos, así como al crecimiento de los mercados. Si durante la etapa clásica del crucerismo a lo largo del siglo XIX y primera mitad del XX las escalas se establecían en virtud de la preexistencia de recursos turísticos explotables ofrecidos por el territorio, hoy día el producto en sí mismo, el viaje en crucero, se sitúa en muchas ocasiones por encima incluso de los atractivos turísticos territoriales como el principal reclamo. En este sentido, coincidimos con autores como Palafox, Cunin, Brida y Zapata, Kester y otros.
El aprovechamiento de los puertos comerciales sigue siendo importante, pero cada vez más las rutas incorporan escalas exclusivas, esto es, destinos que surgen con la única intención de satisfacer la demanda lúdica de este tipo de turismo. Se trata de infraestructuras portuarias específicas para el turismo de crucero. De momento, esta circunstancia afecta tan sólo al Caribe y no a Macaronesia, donde todas las escalas se corresponden con puertos tradicionales, aunque muchos de ellos (Las Palmas, Santa Cruz de Tenerife o Punta Delgada, por citar algunos ejemplos), han invertido en terminales especializadas.

El crecimiento del número de turistas que eligen esta modalidad y la mejora de los barcos están permitiendo diversificar los itinerarios y escalas que se 
TABLA 6

COMPARATIVA ENTRE LOS ÁMBITOS DEL CARIBE Y MACARONESIA

\begin{tabular}{|c|c|c|}
\hline & CARIBE & MACARONESIA \\
\hline Superficie & $191.895 \mathrm{~km}^{2}$ & $10.626 \mathrm{~km}^{2}$ \\
\hline Población & 32.373.000 habitantes & 2.616.500 habitantes \\
\hline Pasajeros estimados (2015) & 25 millones & 1,2 millones \\
\hline Ratio pasajeros de cruceros $/ \mathrm{km}^{2}$ & 130,3 & 112,9 \\
\hline Ratio pasajeros de cruceros / habs & 0,77 & 0,46 \\
\hline $\begin{array}{l}\text { № de Puertos insulares con más de } 10 \\
\text { escalas en } 2018\end{array}$ & 48 & 9 \\
\hline Puertos hubs & $\begin{array}{c}\text { Miami (31,9\%), Fort Lauderdale }(23,2 \%) \text {, } \\
\text { Cabo Cañaveral }(18,4 \%)\end{array}$ & $\begin{array}{c}\text { Gran Canaria }(21,2 \%), \text { Southampton }(18,3 \%), \\
\text { Tenerife }(12,2 \%) \text {, Barcelona }(10,2 \%)\end{array}$ \\
\hline Tipología de puerto dominante & Exclusivo de cruceros & Exclusivo de cruceros \\
\hline Puertos de escala (sin atraque) & Sí & No \\
\hline Puertos en islas privadas & Sí & No \\
\hline Previsión de escalas (2018) & 14.813 & 1.955 \\
\hline Conectividad externa $^{1}$ & Inferior al $10 \%$ & Superior al $65 \%$ \\
\hline Compañías & $\begin{array}{c}\text { Carnival, Royal Caribbean, NCL, Disney, } \\
\text { America Holland }\end{array}$ & Costa Cruceros, MSC, AIDA, TUI \\
\hline Temporalidad & Temporada alta invernal acusada & Temporada alta invernal muy acusada \\
\hline Duración media de las rutas & Predominio rutas de 1 semana & Predominio rutas de 2 semanas \\
\hline Principal actividad turística & $\begin{array}{l}\text { Visita urbana (incluye compras), sol y } \\
\text { playa y actividades acuáticas }\end{array}$ & $\begin{array}{c}\text { Visita urbana (incluye compras) y visita turística } \\
\text { general }\end{array}$ \\
\hline Resort turístico de sol y playa & Sí & No \\
\hline
\end{tabular}

${ }^{1}$. Relación del destino con puertos y rutas fuera del ámbito considerado (incluye los puertos de Florida en el ámbito del Caribe). Elaboración propia

eligen para el viaje. Si a esto sumamos el abaratamiento de precios que ha supuesto el mayor tamaño de los buques y la organización de los servicios de manera coordinada por los turoperadores, hace que el acceso al turismo de crucero sea cada vez más popular a tenor de los datos estadísticos (CLIA, OMT, etc). El crecimiento afecta a los dos ámbitos de estudio, aunque es proporcionalmente mayor en Macaronesia al tratarse de un destino relanzado en la última década.

La competencia de los destinos y el incremento de la demanda están teniendo repercusión en el aumento de las inversiones. Esto se traduce en un cada vez mayor número de dotaciones y servicios, desarrollos portuarios que se ejecutan para resultar competitivos en la carrera por aumentar el número de turistas. Esta circunstancia ha supuesto la transformación reciente de muchos puertos (Cozumel, Barbados, Nassau, Las Palmas, Punta Delgada, Santa Cruz de Tenerife, etc). Las nuevas tendencias de mercado asociadas a su expansión se traducen en una mayor variedad tipológica en cuanto a puertos se refiere. Esta varie- dad tipológica depende de aspectos como la condición y entidad del puerto, su ubicación, las inversiones en infraestructuras especializadas y la disponibilidad de servicios ofertados, e incluso del tipo de recurso que se explota en el destino, esto es, el recurso turístico territorial.

En este sentido, los destinos caribeños evidencian un hecho diferencial como es la utilización del crucero como medio de transporte para acceder a espacios turísticos deficientemente conectados, de tal manera que se llega a muchas islas por medio de cruceros para luego disfrutar de una estancia en tierra en hoteles que son contratados dentro del propio paquete turístico combinado. Esta circunstancia no se ha observado en el ámbito de la Macaronesia, donde resulta más común que el paquete turístico incluya traslados aéreos y salidas desde puertos insulares.

Otra diferencia en cuanto a los destinos del Caribe es que las líneas de crucero más importantes llevan algunos años promocionando escalas en islas privadas de su propiedad (cayos de Great Sirrup, Coco, 
Castaway, Half Moon o Harvest Bay) donde han construido exclusivos resort turísticos e incluso islas artificiales, para crear un atractivo turístico de sol y playa. Sorprende que dentro de una tendencia general del turismo donde los servicios obedecen cada vez más a una tipología personalizada post-fordista se recreen estos destinos que tanto recuerdan las fórmulas más clásicas del turismo de masas. Esta modalidad no está presente por el momento en el ámbito macaronésico, aunque será interesante observar cómo puede evolucionar este destino y si se puede llegar a producir un paralelismo con lo acontecido en el Caribe.

Con respecto a la utilización de los recursos turísticos, ésta viene condicionada por la duración de la escala y la proximidad o lejanía de los mismos respecto al punto de atraque o recalada. Si hasta los años 70 y 80 del pasado siglo la existencia de infraestructuras portuarias eran condición imprescindible a la hora de diseñar las rutas, en la actualidad no sólo existe una mayor oferta, sino que ésta resulta más variada, por lo que los itinerarios se diversifican. Los proveedores de servicio, o lo que es lo mismo, las principales líneas de cruceros, han comenzado a "domesticar" el territorio y crear destinos ex novo, todos ellos basados en estancias de ocio, sol y playa. A los tradicionales recursos visitables, normalmente próximos a los puertos y a distancias abarcables en desplazamientos cortos de no más de 4 o 5 horas, se suman ahora otros atractivos menos habituales, pues el nuevo perfil de usuario de cruceros, mucho más informado, resulta más autónomo al elegir sus actividades en tierra. No obstante, prevalecen las visitas urbanas (que incluye las compras) y las actividades náuticas como primera opción, situándose en tercer lugar las visitas a recursos naturales. Mientras que las dos primeras suelen ser realizadas de manera autónoma, las excursiones siguen siendo el producto que más se contrata para su ejecución en grupo organizado, un aspecto en el que coincidimos con los informes realizados para el Caribe (F-CCA 2018) y Canarias (EDEI 2016) mediante encuestas a los usuarios de crucero. En este sentido, poco más podemos aportar.
En cuanto a las infraestructuras portuarias, se ha observado que existen tres tipos de escalas diferencialmente adaptadas para el turismo de cruceros: las que cuentan con puertos exclusivos de cruceros y disponen de terminales especializadas, las que se llevan a cabo en puertos mixtos comerciales y las que se realizan mediante barcazas con las que se efectúa el desembarco por carecer de medios adaptados para el atraque de cruceros. Estas últimas son exclusivas del Caribe y no se emplean en Macaronesia o son muy inusuales. Los puertos más especializados, esto es, los que podríamos denominar puertos de cruceros, se han adaptado a partir de la transformación de antiguas infraestructuras portuarias obsoletas, la ampliación-rehabilitación dentro de entornos portuarios o incluso se han construido ex profeso como nueva infraestructura especializada en cruceros. Esta especialización ha llegado al extremo de construir resorts aislados y exclusivos, propiedad de las grandes navieras, donde el recurso visitable es generado de forma artificial. Este producto constituye una nueva modalidad dentro del turismo de cruceros, de momento exclusiva del Caribe. Es éste un cambio significativo en la relación entre el territorio y su explotación como recurso turístico, pues el mercado comienza a generar nuevos destinos al modo de los procesos característicos del tradicional turismo de sol y playa. Existe ahora una menor dependencia del territorio y sus recursos turísticos al diseñar las rutas de cruceros.

Por último, es conveniente aclarar que aunque se dispone de abundante información estadística y documental, los datos manejados no siempre evidencian una total fiabilidad. Esto sucede tanto al comparar entre distintas fuentes, que no coinciden plenamente, como incluso contrastando las cifras procedentes de una misma autoridad portuaria. No obstante, pensamos que son carencias de escaso alcance e irrelevantes en el conjunto, de manera que la disponibilidad de datos resulta suficiente para un estudio comparativo de carácter general como el llevado a cabo. 


\section{NOTAS}

1 Este trabajo se enmarca dentro del proyecto de Global South. Puertos y desarrollo económico y social en el Atlántico Meridional. HAR201564044-R MINECO/FEDER, UE.

2 CLIA: Cruise Lines International Association.

3 Organización Mundial del Turismo, Cruise Lines International Association, International Transport Workers' Federation, European Cruise Council,

\section{REFERENCIAS BIBLIOGRÁFICAS}

ACS (2016): Turismo de Cruceros en la Región del Gran Caribe. Dirección de Turismo Sostenible de la AEC-ACS.

Andrade, C. y Robertson, M. (2010): "Turismo de Cruzeiros: perspectivas para a Macaronesia". Turismo \& desenvolvimento, $\mathrm{n}$ ㅇ 13. pp. 265-278.

Andriotis, K. y Agiomirgianakis, G. (2010): “Cruise visitors' experience in a Mediterranean port of call". International Journal of Tourism Research, 12 (4), 390-404. http://dx.doi.org/10.1002/ jtr.770.

Braun, B.M., Dander, J.A., y White, K.R. (2002): “The impact of the cruise industry on a region's economy: a case study of Port Canaveral, Florida". Tourism Economics 8(3), pp. 281-288.

Brida, J. G. y Zapata, S. (2008): "The impacts of the cruise industry on tourism destinations". Sustainable tourism as a factor of local development. Monza, 7-9/11/2008. http://ssrn.com/abstract=1298403 (Fecha de consulta: 21/11/2017).

Brida, J.G. y Zapata, S. (2010): “Cruise tourism: economic, socio-cultural and environmental impacts". International Journal of Leisure and Tourism Marketing 1(3), pp. 205-226.

Brida, J. G., Bukstein, D, y Tealde, E. (2015): “Exploring Cruise Ship Passenger Spending Patterns in Two Uruguayan Ports of Call." Current Issues in Tourism 18 (7): 684-700.

Butler, M. (2008): Turismo de cruceros. Situación actual y tendencias. Organización Mundial del Turismo. Madrid.

César-Dachary, A. (1996): "Desarrollo sustentable, turismo y medio ambiente en el Caribe ¿Una op-
Association of Caribean States, Florida-Caribbean Cruise Association.

4 http://www.onecaribbean.org/statistics/historicaldata-1970-2015/.

5 Revista del Sector marítimo. Ingeniería naval (2015). En línea. [consultada: 7/2/20].

6 https://www.ncl.com/es/es/Harvest-Caye-h3uoi/

ción válida?". Estudios y perspectivas en turismo, vol. 5, pp. 18-51.

CLIA (2017). Anual Report, 2017. Cruise Lines International Association. (Fecha de consulta: 5/1/19). https://cruising.org/news-and-research/research/2017/december/2017-annual-report

Crusie Industry News, Annual Report 2018 (2018). [Consultada 15/4/19]. https://www.cruiseindustrynews.com/store/product/annualreports/2019-cruise-industry-news-annualreport/

Cruz Ruiz, E. y Romero de la Cruz, E. (2015): "Tendencias y estrategias en la industria del crucero: principales áreas del turismo de cruceros en el mundo", en TURyDES Revista de Investigación en Turismo y Desarrollo Local, vol 8, no 19. (Fecha de consulta: 2/11/18). http://cort.as/-IE4|

Cunin, E. (2006): “Escápate a un mundo...fuera de este mundo: Turismo, Globalización y Alteridad. Los cruceros por el Caribe en Cartagena de Indias (Colombia)", en Boletín de antropología, año/ vol.20, no 037, Universidad de Antioquia, Medellín, Colombia, pp.131-151.

Dwyer L. y Forsyth P. (1998): “Economic significance of cruise tourism". Annals of Tourism Research 25, pp. 393-415. http://dx.doi.org/10.1016/ S0160-7383(97)00098-4.

EDEI (2005, 2009 y 2016). Estudio del Mercado de cruceros en Canarias. Gobierno de Canarias y Autoridades Portuarias de Las Palmas y Tenerife. Memoria quinquenal.

Esteve-Pérez, J., García-Sánchez, A. y Gutiérrez, J. (2015): “Estacionalidad del tráfico de cruceros en las Islas Canarias y la complementariedad entre rutas de crucero", Anuario Jóvenes Investigadores, junio 2015, n. 8, pp. 51-53. 
F-CCA (2018). Economic contribution of cruise tourism to the destination economies. (Fecha de consulta: 2/2/2019). https://www.f-cca.com/downloads/ Caribbean-Cruise-Analysis-2018-Vol-I.pdf

Fernández, L. (2009): “Acontecer del turismo de cruceros en Cuba y sus potencialidades para el mercado norteamericano". TURyDES Revista de Investigación en Turismo y Desarrollo Local 2(6): s/n.

Fernández Miranda, R. (2012): Lo que hunden mientras flotan. Auge y análisis crítico del turismo de cruceros en la globalización. Alba Sud. https:// n9.cl/th0o (Fecha de consulta: 6/12/2018).

Fernández, A y Mayorga, M. (2018): “Estacionalidad del turismo de cruceros en puertos españoles". Pasos. Revista de Turismo y Patrimonio Cultural, 16 nำ. Universidad de La Laguna. La Laguna.

Fernández-Morales, A. y Cisneros-Martínez, J. D. (2019): "Seasonal Concentration Decomposition of Cruise Tourism Demand in Southern Europe". Journal of Travel Research, 58 (8), 1389-1407. https://doi.org/10.1177/0047287518802094 .

Garay, L. y Cànoves, G (2012): "Turismo de cruceros en Barcelona. De la marginalidad al liderazgo internacional". Boletín de la Asociación Española de Geógrafos, 60, pp. 253-271.

González, A. y Ramón, A. (2017): “La planificación del espacio portuario de Gran Canaria en sus primeras etapas de desarrollo (1883-1990)". V Congreso Internacional de la Gobernanza de los puertos atlánticos. Las Palmas de Gran Canaria. Diciembre 2017.

Hernández, J. Del Chiappa, G. y Battino, S. (2015): "Percepción de los residentes de las Palmas de Gran Canaria ante el turismo de cruceros", Vegueta, no 15, pp. 287-316.

Honey, M. (2017): Lessons Learned from 50 Years of Cruise Tourism in the Caribbean. CREST (Center for Responsible Travel). Montego Bay. Jamaica.

ITF (2014): Annual Report 2013. Londres: International Transport Workers' Federation Press.

Kester, J.G.C. (2002): “Cruise tourism”. Tourism Economics, 9, pp. 337-350.

Lee, Scott \& Ramdeen, Collin, 2013. "Cruise ship itineraries and occupancy rates". Tourism Management, Elsevier, vol. 34(C), pages 236-237. DOI: 10.1016/j.tourman.2012.03.009.

Legoupil, T. (2013). "Los conflictos que genera el turismo de cruceros en Barcelona y otros puertos mediterráneos". Biblio 3W. Revista Bibliográfica de Geografía y Ciencias Sociales, núm. 1049.

Luna Buades, M. (2015): “El turismo de cruceros en el Mediterráneo y en las Illes Balears. Un análisis entre el 2000 y el 2012". Scripta Nova. Universidad de Barcelona, vol. 19, № 514. Barcelona.

Martí, B. (1990): "Geography and the cruise ship port selection process". Maritime Policy \& Management 17(3). July 1990, pp. 157-164.

Martín Galán, F. (2001): Las Palmas. Ciudad y Puerto. Fundación Puertos de Las Palmas.

Murias López, R. (2002): La industria del crucero en el siglo XXI. Implicación en los puertos españoles $y$ perspectivas de futuro. Barcelona: Universitat Politècnica de Catalunya.

OMT, Organización Mundial del Turismo (2008): Turismo de cruceros Situación actual y tendencias. OMT, Madrid.

Palafox et al (2015): “Cozumel y la transformación de su paisaje por el turismo de cruceros". Revista de Ciencias Sociales [en línea] 2015, III (Fecha de consulta: 7/2/2018) Disponible en: http://www. redalyc.org/articulo.oa?id=15343488008.

Ramón A. y González, A. (2017): “La integración urbanística de los proyectos y planes portuarios. El caso de Las Palmas de Gran Canaria". V Congreso Internacional de la Gobernanza de los puertos atlánticos. Las Palmas de Gran Canaria. Diciembre 2017.

Revista del Sector marítimo. Ingeniería naval (2015). https://sectormaritimo.es/los-diez-buques-decrucero-mas-grandes-del-mundo (Fecha de consulta: $7 / 2 / 2020$ ).

Rodrigue, J., y Notteboom, T. (2013): “The Geography of Cruises: Itineraries, not Destinations." Applied Geography 38, pp. 31-42.

Sainaghi, R., Mauri, A. y d’Angella, F. (2019): “Decomposing seasonality in an urban destination: the case of Milan". Current Issues in Tourism, 22:16, 19191924, DOI: 10.1080/13683500.2018.1493094.

Santander, L. y Ramos, M. (2011): “El nacimiento de un destino turístico en el Caribe Mexicano. Cozumel, de isla abandonada a puerto de cruceros". El Periplo Sustentable 2011 [en línea], (Julio-Diciembre). (Fecha de consulta: 28/1/2018]. Disponible en: https://rperiplo.uaemex.mx/article/ view/5013. 
Seidl, A., Guiliano, F. y Pratt, L. (2006): “Cruise tourism and community economic development in Central America and the Caribbean: The case of Costa Rica", Pasos, 4 (2), pp. 213-224.

Showalter, G. (1995) "Cruise Ships and Private Islands in the Caribbean", Journal of Travel \& Tourism Marketing, 3:4, 107-118, DOI: 10.1300/ J073v03n04_07.

Silvestre, A., Santos, C. y Ramalho, C. (2008): "Satisfaction and behavioral intentions of cruise passengers visiting the Azores". Tourism Economics, 14 (1), 169-184. http://dx.doi.org/10.5367/ 000000008783554802.

Teye, V. y Morris, C. (2011). “Cruise Line Industry and Caribbean Tourism: Guests' Motivations, Activi- ties and Destination Preference". Tourism Review International, vol 14, pp. 17-28.

Timothy, D. (2006): Cruises, supranationalism and border complexities. Oxfordshire: CABI. http:// dx.doi.org/10.1079/9781845930486.0407.

Wood, R. E. (2000): “Caribbean cruise tourism: Globalization at sea". Annals of Tourism Research, 27 (2), 345-370. http://dx.doi.org/10.1016/ S0160-7383(99)00073-0.

WTO, World Tourism Organization (2018), UNWTO Annual Report 2017, UNWTO, Madrid, DOI: https://doi.org/10.18111/9789284419807. 